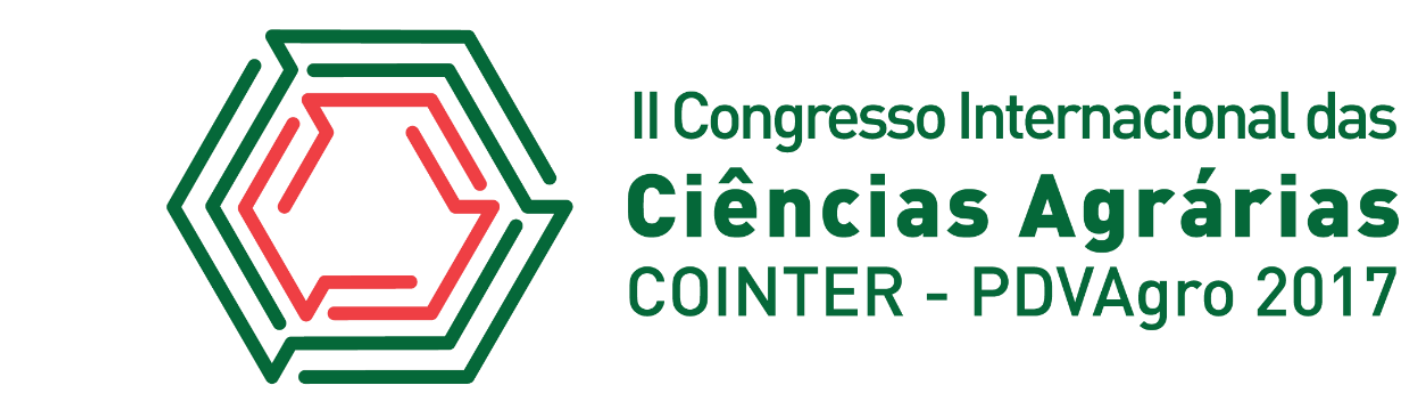

\title{
EFICIÊNCIA DE INSETICIDAS SOBRE Spodoptera frugiperda (J.E. SMITH, 1797) (LEPIDOPTERA: NOCTUIDAE)
}

\author{
Apresentação: Pôster
}

Antonio Carlos Leite Alves ${ }^{1}$; Gemerson Machado de Oliveira ${ }^{2}$; Heloísa Martins de Araújo ${ }^{2}$; Izabela Nunes do Nascimento ${ }^{1}$; Jacinto de Luna Batista ${ }^{3}$

\section{Introdução}

O milho Zea mays L. é um dos cereais mais cultivados no mundo, no Brasil ocupa a terceira posição no ranking dos países mais produtores (USDA, 2017). Mesmo com tanta importância para o agronegócio brasileiro, esta cultura ainda apresenta frequente redução de produtividade em função do ataque de pragas, principalmente da lagarta Spodoptera frugiperda.

A espécie $S$. frugiperda é uma mariposa da família Noctuidae, conhecida popularmente como lagarta-do-cartucho do milho, é considerada uma das espécies praga mais nociva desta cultura por apresentar incidência durante todo o ano (Nagoshi et al., 2007). A lagarta-do-cartucho destacase pela redução da produtividade e da qualidade do produto final, como também pela dificuldade de controle (Nebo et al., 2010).

A forma de controle para $S$. frugiperda mais utilizada é através do uso de inseticidas sintéticos, foram até o momento registrados 174 produtos para essa praga pelo Ministério da Agricultura. Sendo a aplicação desses inseticidas deve ser direcionada para o cartucho e em épocas de grande umidade (AGROFIT, 2017).

Sabe-se que se os agricultores ao usarem os produtos químicos de forma incorreta, com relação a produtos ou dosagens acima das recomendadas, além de outros problemas pode ocorrer a seleção de insetos resistentes e aumento no custo de produção. Diante do exposto, objetivou-se com esse estudo avaliar a eficiência de dois inseticidas $\left(\right.$ Premio $^{\circledR}$ e Dipel ${ }^{\circledR}$ ) registrado para a cultura do milho, assim como também ver a relação custo/benefício.

\section{Fundamentação Teórica}

Na literatura é possível encontrar vários trabalhos avaliando o uso de moléculas químicas sobre a lagarta-do-cartucho, Figueiredo et al. (2006), observaram o efeito do inseticida chlorpyrifos e sua interação com inimigos naturais na supressão de $S$. frugiperda na cultura do milho.

\footnotetext{
${ }^{1}$ Pós-Graduação em Agronomia (PPGA), Centro de Ciências Agrárias (CCA) da Universidade Federal da Paraíba (UFPB), e-mail: carlos.ufca@yahoo.com.br; izabelaufpb@gmail.com

${ }^{2}$ Graduação em Agronomia, Centro de Ciências Agrárias (CCA) da Universidade Federal da Paraíba (UFPB), e-mail: gemerson.oliveira@hotmail.com;

${ }^{3}$ Professor Associado IV, Programa de Pós-Graduação em Agronomia (PPGA), Centro de Ciências Agrárias (CCA) da Universidade Federal da Paraíba (UFPB), e-mail: jacinto@cca.ufpb.br
} 
Tomquelski e Martins (2007), fizeram estudos no Estado de Mato Grosso do Sul, avaliando a eficiência de inseticidas sobre $S$. frugiperda em milho. Os mesmos, verificaram diferenças estatísticas entres os produtos químicos utilizados.

Uma das preocupações que existe no meio agrícola, é o uso frequente de moléculas químicas que possam trazer problemas de ordem diversa ao homem e ambiente. Dentre os vários grupos de inseticidas modernos tem-se, os produtos biológicos, cujo o principal princípio ativo é o Bacillus thurigiensis, sendo considerado um produto químico classe IV, ou seja, pouco perigoso ao meio ambiente. $\mathrm{O}$ inseticida Premio ${ }^{\circledR}$ é classificado quando a periculosidade ambiental como classe II, muito perigoso ao meio ambiente.

\section{Metodologia}

O ensaio experimental foi conduzido no Laboratório de Entomologia da Universidade Federal da Paraíba (LEN/UFPB), Campus de Areia-Paraíba. Utilizou-se lagarta no $5^{\circ}$ instar de Spodoptera frugiperda provenientes da criação em laboratório.

\section{Criação Spodoptera frugiperda}

A colônia inicial de $S$. frugiperda foi estabelecida com insetos coletados individualmente na fazenda experimental do CCA/UFPB. As lagartas foram conduzidas ao laboratório (UR: $70 \pm 10 \%$, $\mathrm{T}: 25^{\circ} \pm 1^{\circ} \mathrm{C}$ e fotofase de 12 horas) e individualizadas em placas de Petri (90 mm x $15 \mathrm{~mm}$ ), sendo alimentadas inicialmente com folhas de milho. Diariamente foi realizada a renovação do alimento até a fase pupal. Após a emergência casais foram transferidos para tubos de PVC (cloreto de polivinila) de $20 \mathrm{~cm}$ de diâmetro por $20 \mathrm{~cm}$ de altura revestido internamente com papel sulfite, com a extremidade superior coberta por tecido "voil" e inferior tampada com material plástico. Para os adultos foi oferecido como alimento uma solução de água e mel a 10\%. As posturas obtidas nos tubos foram coletadas e transferidas para placas de "Petri" esterilizadas, forradas internamente com papel de filtro. Após a eclosão, as lagartas foram individualizadas em tubos de vidro de fundo chato de 2,5 cm de diâmetro x 8,5 cm de comprimento, alimentando-se de dieta artificial, cujo o conteúdo foi preenchido até $1 / 4$ da altura dos tubos, estes foram tamponados com algodão e mantidos em câmara climatizada.

\section{Aplicação dos Tratamentos}

Utilizou-se o delineamento experimental inteiramente casualizado, em esquema fatorial $3 \times 15$, correspondendo a três tratamentos, sendo dois produtos químicos registrados para a cultura do milho Z. mays, e uma testemunha com água destilada. Foi realizado aplicação tópica dos inseticidas, com auxílio de um borrifador manual e o volume de calda usado em cada repetição foi de $1,5 \mathrm{~mL}$. Os produtos foram aplicados na dosagem recomenda por cada fabricante para a cultura 
do milho (Tabela 1). Para cada tratamento, utilizaram-se quinze repetições, onde cada repetição correspondia a uma lagarta de $5^{\circ}$ instar de $S$. frugiperda, os insetos foram individualizados em e placas de Petri de $9 \mathrm{~cm}$ de diâmetro por $2 \mathrm{~cm}$ de altura. Após a aplicação dos tratamentos as placas de Petri ficaram expostas a ambiente controlado, com temperatura de $25,0 \pm 1{ }^{\circ} \mathrm{C}$ e umidade relativa de $70 \pm 10 \%$. A avaliação do número de insetos mortos, foi realizado 36 horas após aplicação dos inseticidas químicos.

Tabela 1. Nome comercial, grupo químico e dosagens dos inseticidas utilizados no teste de eficiência, Areia-PB, 2017.

\begin{tabular}{cccc}
\hline Nome Comercial & Ingrediente ativo & Doses $(\mathbf{p . c} / \mathbf{L}$ de água) & Grupo químico \\
\hline DiPel $^{\circledR}$ & Bacillus thurigiensis & $10 \mathrm{~mL} / \mathrm{L}$ & Biológico \\
Premio $^{\circledR}$ & Clorantraniliprole & $1,25 \mathrm{~mL} / \mathrm{L}$ & Diamida \\
\hline
\end{tabular}

\section{Análise estatística}

Os dados obtidos foram submetidos à análise de Deviance Andeva, para o modelo binomial e as médias comparadas pelo teste do Qui-quadrado $\left(\chi^{2}\right) .(\mathrm{P} \leq 0,01)$.

\section{Resultados e Discussões}

\section{Eficiência dos inseticidas sobre $S$. frugiperda}

Ao avaliar a eficiência de inseticidas sobre lagartas de $5^{\circ}$ instar de Spodoptera frugiperda, verificou-se diferença estatística significativa entre todos os tratamentos (Testemunha, Premio ${ }^{\circledR} \mathrm{e}$ Dipel $^{\circledR}$ ), pelo teste do Qui-quadradro $\left(\chi^{2} \leq 0,01\right)$ (Figura 1). O inseticida que apresentou maior proporção de mortalidade foi o Dipel $^{\circledR}$ (probabilidade=0,93), isto é, causou quase $100 \%$ de mortalidade S. frugiperda. O agroquímico Premio ${ }^{\circledR}$, apresentou menor eficácia no efeito da mortalidade dessa praga (probabilidade $=0,33$ ).

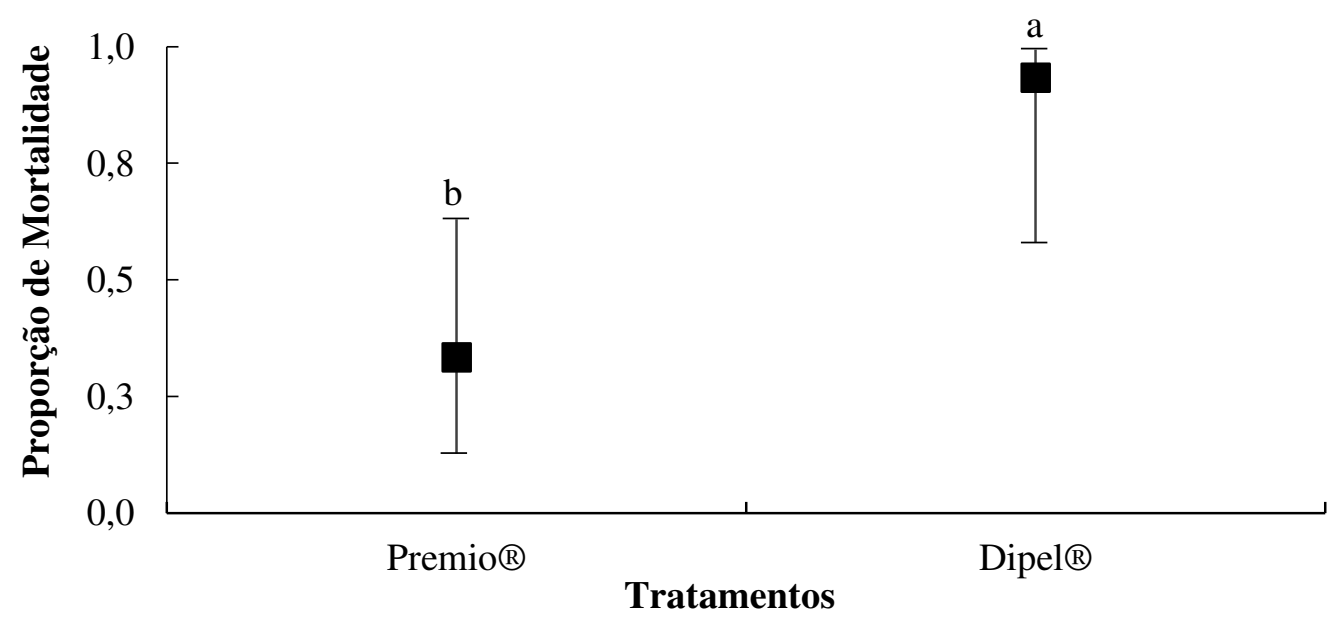

Figura 1. Intervalos de confiança e Proporção de mortalidade de S. frugiperda submetido aos tratamentos com inseticidas químicos $\left(\right.$ Premio $^{\circledR}$ e Dipel $^{\circledR}$ ), Areia-PB, 2017. Fonte: Própria. 
No tratamento controle, sem aplicação de inseticida, não se observou mortalidade de lagarta no intervalo de 36 horas após aplicação dos tratamentos.

Em estudo de manejo e controle de pragas de milho safrinha, Grigolli (2015) observou eficiência de $33 \%$ de mortalidade de S. frugiperda nas primeiras 24 horas após aplicação do inseticida Premio ${ }^{\circledR}$, no entanto quando avaliado a mortalidade 4 dias após aplicação constatou-se uma mortalidade de $79 \%$, resultados que corroboram ao desta pesquisa, que observou-se uma eficiência de mortalidade $33 \%$ nas primeiras 36 horas.

De acordo com o fabricante, o princípio ativo do inseticida Dipel ${ }^{\circledR}$ é Bacillus thuringiensis, var. kurstak linhagem HD-1, Silva-Werneck et al. (2000) avaliando esse mesmo isolado sobre a lagarta-do-cartucho, constataram uma mortalidade de $100 \%$ em lagartas de $3^{\circ}$ instar. Resultados semelhantes foram observados nesse estudo, no entanto as formas de aplicação dos produtos são divergentes.

Na figura 2, observam-se lagartas de $5^{\circ}$ instar, quando submetidos ao inseticida Dipel ${ }^{\circledR}$, nota-se que o inseto apresenta coloração escura e aparência de flacidez tegumentar.
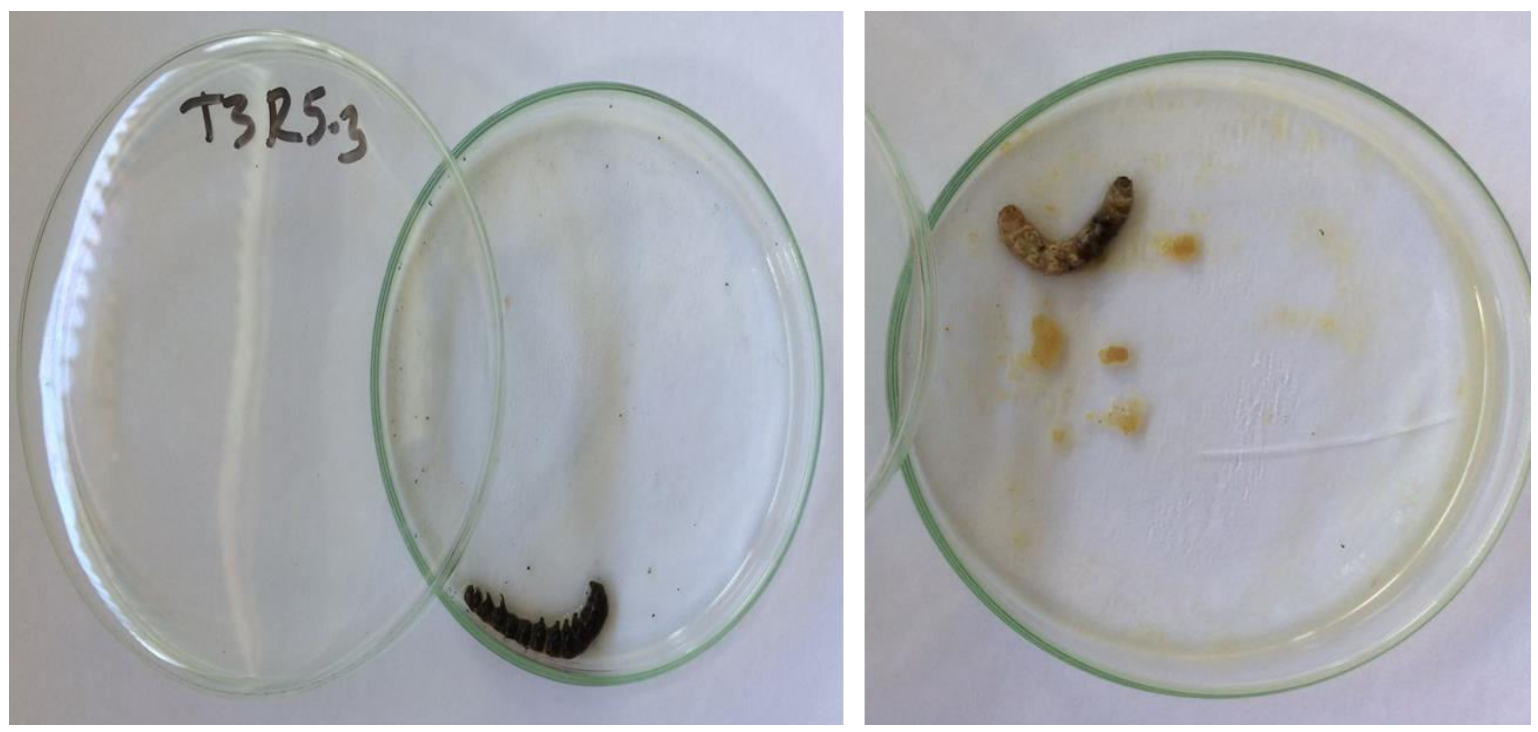

Figura 2. Aspecto visual de S. frugiperda quando submetido ao inseticida Dipel ${ }^{\circledR}$. Areia-PB, 2017. Fonte: Própria.

\section{Relação custo/benefício}

Considerando a comparação entre os dois produtos utilizados nessa pesquisa, para os fatores eficiência x custo do tratamento controle de S. Frugiperda. Na tabela 2, observa-se o valor dos produtos químicos encontrados em uma loja agropecuária no município de Campina Grande-PB, assim como a quantidade recomendada do produto pelo fabricante. Nota-se que o inseticida biológico apresentou custo/ciclo da cultura $36 \%$ mais barato que o inseticida Premio ${ }^{\circledR}$. 
Tabela 2. Relação custo/benefício entres os inseticidas Dipel ${ }^{\circledR}$ e Premio ${ }^{\circledR}$. Areia-PB, 2017. Fonte: Própria.

\begin{tabular}{ccccc}
\hline Produtos & Valor unitário $(\mathbf{R} \$)$ & $\begin{array}{c}\text { Quantidade do } \\
\text { Produto/ha }\end{array}$ & $\begin{array}{c}\text { Número de } \\
\text { Aplicações }\end{array}$ & $\begin{array}{c}\text { Custo/ciclo da } \\
\text { cultura (R\$) }\end{array}$ \\
\hline Dipel $^{\circledR}$ & $80,00(1 \mathrm{~L})$ & $1 \mathrm{~L}$ & 3 & 240,00 \\
Premio $^{\circledR}$ & $200,00(200 \mathrm{~mL})$ & $125 \mathrm{~mL}$ & 3 & 375,00 \\
\hline
\end{tabular}

\section{Conclusões}

Com base nos resultados obtidos nessa pesquisa, o inseticida Dipel ${ }^{\circledR}$ nas primeiras 36 horas é mais eficaz que o Premio ${ }^{\circledR}$ no controle de Spodoptera frugiperda em laboratório;

O inseticida Premio ${ }^{\circledR}$ apresenta eficiência de mortalidade $60 \%$ menor que o Dipel ${ }^{\circledR}$, tendo uma projeção de 135,00 reais mais caro para se fazer o controle dessa praga em um hectare.

\section{Referências}

AGROFIT. Sistemas de agrotóxicos fitossanitários. Disponível em: <http://agrofit.agricultura.gov.br/agrofit_cons/principal_agrofit_cons>. Acesso em 11/10/2017.

FIGUEIREDO, M.L.C.; MARTINS-DIAS, A.M.P.; CRUZ, I. Efeito do inseticida chlorpyrifos e sua interação com inimigos naturais na supressão de Spodoptera frugiperda (J.E. SMITH, 1797) (Lepidoptera: Noctuidae) na cultura do milho. Revista Brasileira de Milho e Sorgo, v.5, n.3, p.325-339, 2006.

GRIGOLLI, J.F.J. Manejo e Controle de Pragas do Milho Safrinha. p.13, 2015.

NAGOSHI, R.N.; SILVIE, P.; MEAGHER, L.R.; LOPEZ, J.; MACHADO, V. Identification and Comparison of fall armyworm (Lepidoptera: Noctuidae) host strains in Brazil. Annals of the Entomological Society of America, v. 100, n. 3, p. 394-402, 2007.

NEBO, L., MATOS, A.P., VIEIRA, P.C., FERNANDES, J.B., SILVA, M.F.G.F., RODRIGUES, R.R. Atividade inseticida dos frutos de Trichilia claussenii (MELIACEAE) sobre Spodoptera frugiperda. Quimica Nova, v. 33, n. 9, p. 1849-1852, 2010.

SILVA-WERNECK, J.O.; ABREU NETO, J.R.M.V.; TOSTES, A.N.; FARIA, L.O.; DIAS, J.M.C.S. Novo isolado de Bacillus thuringiensis efetivo contra a lagarta-do-cartucho. Pesquisa agropecuária brasileira, v.35, n.1, p.221-227, 2000.

TOMQUELSKI, G. V.; MARTINS, G.L.M. Eficiência de inseticidas sobre Spodoptera frugiperda (J.E. SMITH, 1797) (Lepidoptera: Noctuidae) em milho na Região dos Chapadões. Revista Brasileira de Milho e Sorgo, v.6, n.1, p. 26-39, 2007.

USDA-United States Department of Agriculture. Grain:World Markets and Trade. 2017, 52 p. 